\title{
RECONOCIMIENTO CONSTITUCIONAL DE NIÑOS, NIÑAS Y ADOLESCENTES Y SU IMPACTO \\ EN LA RESPONSABILIDAD CIVIL \\ DE LOS PADRES
}

\section{CONSTITUTIONAL ACKNOWLEDGEMENT OF CHILDREN AND YOUTH AND ITS IMPACT ON LIABILITY FOR PARENTS}

Antonio Olivares Contreras*

Constanza Fuentes López ${ }^{* *}$

Mira niño ya me has hecho mucho daño [...] ¿Por qué no vas a jugar a la plaza? No puedo ir mi madre trabaja. Pepe Lota, 31 minutos.

\section{RESUMEN}

Desde el posible reconocimiento constitucional de los derechos de las niñas, niños y adolescentes, así como de la corresponsabilidad parental en una nueva Constitución chilena, abordaremos la recepción de dichos cambios en las normas de responsabilidad civil de los padres. En lo medular, sostendremos que el actual sistema de responsabilidad civil de los padres en el Código Civil chileno requiere un reemplazo de los criterios de subsidiariedad y habitabilidad, dando paso a la corresponsabilidad parental y la autonomía progresiva del niño, niña o adolescente, como elementos centrales para abordar la responsabilidad civil de los padres por los daños cometidos por sus hijos a la luz de una nueva Constitución.

*Abogado. Universidad de Chile. Ayudante cátedra Derecho Civil. Correo electrónico: antonio.olivares@derecho.uchile.cl

** Abogada. Universidad de Chile. Ayudante cátedra Derecho Civil. Correo electrónico: coni.fuentes20@gmail.com

Recepción: 2021-05-23; aceptación: 2021-08-03. 
Palabras Clave: Corresponsabilidad parental; responsabilidad civil de los padres; derechos de NNA; autonomía progresiva del niño.

\section{Abstract}

This paper is built from the possible constitutional acknowledgement of children and teenager's rights as well as parental joint responsibility on the new Chilean Constitution. Based on this premise, we have focused on parental liability resulting from the damages committed by their children. For that purpose, we argue that the current parental liability system on the Chilean Civil Code requires a complete update, replacing the elements of subsidiarity and habitability to parental joint responsibility and progressive autonomy of the child as main elements to address parental liability under the scope of a new Constitution.

Keywords: Parental joint responsibility; Parental liability, Children's rights; Progressive autonomy of the child.

Salvo por la aplicación de los tratados internacionales suscritos por Chile -y sin perjuicio de la discusión desde luego conocida sobre su rango legal-, nuestro país no cuenta con normas constitucionales que regulen directamente aspectos ligados a la familia o a los derechos de los NNA.

Así, el panorama nacional se muestra desolador, pues mientras varias naciones latinoamericanas han reconocido tanto a los NNA como sus derechos en sus Constituciones, Chile solo ha incursionado en algunas tímidas reformas ${ }^{1}$.

Sin embargo, el actual escenario constitucional es propicio para pensar cómo una nueva Constitución puede influir en la aplicación de las normas de derecho privado. En efecto, en este trabajo pretendemos abordar las posibles implicancias que pudiera conllevar un reconocimiento expreso de los NNA como sujetos de derecho, el reconocimiento de derechos fundamentales específicos en su favor y la consagración de algunos principios del derecho de familia en la Constitución, en las reglas de responsabilidad civil de los padres respecto de los daños ocasionados por sus hijas e hijos o, dicho de otro modo, si dicho reconocimiento requerirá adaptar la responsabilidad civil de los padres, actualmente consagrada. Con aquel

\footnotetext{
${ }^{1}$ Ya se ha dado cuenta de esta situación en Lathrop (2014), pp. 197-229; BASSA (2018).
} 
objetivo en mente, plantearemos una propuesta para adaptar las normas específicas referidas a la responsabilidad de los padres del Código Civil como respuesta a una regulación constitucional.

Para reflexionar sobre la forma en que la Constitución podrá establecer normas y directrices sobre el derecho de familia, nos concentraremos tanto en el derecho comparado como en los tratados internacionales que sean útiles a la hora de discurrir en una nueva regulación de derecho interno.

\section{PANORAMA CONSTITUCIONAL COMPARADO \\ EN TORNO A NNA}

La actual Constitución Política de la República de Chile no reconoce ni consagra los derechos de los NNA, ni tampoco presenta mayores referencias a la infancia. Los pocos acercamientos que se podrían asimilar tienen relación con el reconocimiento y protección de la familia, o con la libertad de enseñanza de los padres, o, bien, con la igualdad entre los hijos, pero no existe una consagración en el ámbito constitucional de los derechos de los NNA ${ }^{2}$. Esta situación contrasta con una gran cantidad de Estados que han hecho expresa referencia a ellos y a sus derechos en sus respectivas Constituciones.

De tal manera, la Constitución argentina reconoce una jerarquía superior a los tratados internacionales dándole especial valor a algunos como la $\mathrm{CDN}^{3}$. A su vez, establece un deber al legislador para que promueva medidas de acción positiva que garanticen el pleno goce y ejercicio de los derechos reconocidos por la Constitución, en particular respecto de los niños. Demostrando con ello que los niños y niñas son titulares de derechos con especial consideración en razón de su nivel de vulnerabilidad frente a otras personas ${ }^{4}$.

${ }^{2}$ Art. . $^{\circ}$ inciso segundo, art. 10 , art. 19 n. ${ }^{\circ} 10$ y el art. 19 n. ${ }^{\circ} 11$ de la Constitución Política de la República chilena. En ese sentido también lo ha sostenido ETCHEBERRY (2020).

${ }^{3}$ Constitución Política argentina art. 75 numeral 22 "Los tratados y concordatos tienen jerarquía superior a las leyes". Enseguida el mismo numeral señala una serie de tratados internacionales de derechos humanos, entre los que menciona la $\mathrm{CDN}$, para agregar: “[...] en las condiciones de su vigencia, tienen jerarquía constitucional, no derogan artículo alguno de la primera parte de esta Constitución y deben entenderse complementarios de los derechos y garantías por ella reconocidos".

${ }^{4}$ Constitución Política argentina art. 75 numeral 23: "Legislar y promover medidas de acción positiva que garanticen la igualdad real de oportunidades y de trato, y el pleno goce y ejercicio de los derechos reconocidos por esta Constitución y por los tratados internacionales vigentes sobre derechos humanos, en particular respecto de los niños, las mujeres, los ancianos y las personas con discapacidad". 
Por su parte, la Constitución de los Estados Mexicanos no solo menciona en varias disposiciones a los $\mathrm{NNA}^{5}$, sino que establece que en todas las decisiones y actuaciones del Estado se velará y cumplirá con el principio del interés superior de la niñez ${ }^{6}$. También parece ejemplificadora la Constitución Política de Ecuador, que reconoce una sección completa para niñas, niños y adolescentes, además de indicar que constituyen un grupo que recibirá atención prioritaria y especializada en los ámbitos público y privado ${ }^{7}$. Pero destacamos especialmente para los efectos de este trabajo que su Constitución reconoce el principio de corresponsabilidad materna y paterna ${ }^{8}$.

En la Constitución española, por cierto, su capítulo de "Principios rectores de la política social y económica" parte señalando no solo que los niños gozan de la protección prevista en los acuerdos internacionales, sino que "los padres deben prestar asistencia de todo orden a los hijos" ${ }^{\text {. En el }}$ mismo orden de ideas, la Constitución Política de Uruguay indica que el cuidado y la educación de los hijos para que alcancen su plena capacidad es un derecho y deber de los padres. Lamentablemente la Constitución de Uruguay tampoco hace una mención expresa a NNA, pero al menos

${ }^{5}$ Constitución Política de los Estados Unidos Mexicanos, art. 3: "La educación inicial es un derecho de la niñez y será responsabilidad del Estado concientizar sobre su importancia. [...] El Estado priorizará el interés superior de niñas, niños, adolescentes y jóvenes en el acceso, permanencia y participación en los servicios educativos". Art. 4. ${ }^{\circ}$ : "El Estado otorgará facilidades a los particulares para que coadyuven al cumplimiento de los derechos de la niñez".

${ }^{6}$ Constitución Política de los Estados Unidos Mexicanos, art. $4^{\circ}$ inciso 9: "En todas las decisiones y actuaciones del Estado se velará y cumplirá con el principio del interés superior de la niñez, garantizando de manera plena sus derechos. Los niños y las niñas tienen derecho a la satisfacción de sus necesidades de alimentación, salud, educación y sano esparcimiento para su desarrollo integral. Este principio deberá guiar el diseño, ejecución, seguimiento y evaluación de las políticas públicas dirigidas a la niñez".

${ }^{7}$ Constitución Política de Ecuador, art. 35: "Las personas adultas mayores, niñas, niños y adolescentes, mujeres embarazadas, personas con discapacidad, personas privadas de libertad y quienes adolezcan de enfermedades catastróficas o de alta complejidad, recibirán atención prioritaria y especializada en los ámbitos público y privado. La misma atención prioritaria recibirán las personas en situación de riesgo, las víctimas de violencia doméstica y sexual, maltrato infantil, desastres naturales o antropogénicos. El Estado prestará especial protección a las personas en condición de doble vulnerabilidad".

${ }^{8}$ Constitución Política de Ecuador, art. 69 numeral 5. : "Para proteger los derechos de las personas integrantes de la familia: El Estado promoverá la corresponsabilidad materna y paterna y vigilará el cumplimiento de los deberes y derechos recíprocos entre madres, padres, hijas e hijos".

${ }^{9}$ Constitución Política española, art. 39 numerales 3 y 4: "Los padres deben prestar asistencia de todo orden a los hijos habidos dentro o fuera del matrimonio, durante su minoría de edad y en los demás casos en que legalmente proceda. 4. Los niños gozarán de la protección prevista en los acuerdos internacionales que velan por sus derechos". 
reconoce que la ley dispondrá medidas para que la infancia y juventud sean protegidas ${ }^{10}$. Destaca también la Constitución de la República Federativa de Brasil la cual indica, en un capítulo dedicado a la familia, al niño, adolescente y al anciano un artículo especial referido al deber de los padres de asistir, criar y educar a sus hijos ${ }^{11}$.

Finalmente, observamos que la Constitución Política de Colombia describe una serie de derechos fundamentales de los niños, para luego indicar que la familia, la sociedad y el Estado tienen el deber de protegerlos para garantizar su desarrollo armónico y el ejercicio pleno de sus derechos. Luego concluye que "Los derechos de los niños prevalecen sobre los derechos de los demás" (énfasis añadido) ${ }^{12}$. Cabe destacar que el Comité de Derechos del Niño ha identificado un principio de prioridad para hacer efectivos los derechos de la infancia, lo cual importa una prioridad que influya en el gasto público de los Estados, pues solo de esa manera se puede lograr la efectiva implementación de sus derechos ${ }^{13}$.

Ahora bien, respecto a la situación actual del Estado chileno conviene recordar que el año 1990 ratificó la $\mathrm{CDN}$, por lo que en virtud del art. $5^{\circ}$ inciso segundo de la actual Constitución, dicha normativa forma parte de la legislación interna. De este modo, el art. 18 de la CDN tiene plena aplicación en Chile al indicar:

${ }^{10}$ Constitución Política de Uruguay, art. 41: "El cuidado y educación de los hijos para que éstos alcancen su plena capacidad corporal, intelectual y social, es un deber y un derecho de los padres. Quienes tengan a su cargo numerosa prole tienen derecho a auxilios compensatorios, siempre que los necesiten.

La ley dispondrá las medidas necesarias para que la infancia y juventud sean protegidas contra el abandono corporal, intelectual o moral de sus padres o tutores, así como contra la explotación y el abuso".

${ }^{11}$ Constitución de la República Federativa de Brasil, art. 229: "Los padres tienen el deber de cuidar, criar y educar a los hijos menores, y los hijos mayores de edad tienen el deber de cuidar y amparar a sus padres en la vejez, la necesidad o la enfermedad".

${ }^{12}$ Constitución Política de Colombia, art. 44: "Son derechos fundamentales de los niños: la vida, la integridad física, la salud y la seguridad social, la alimentación equilibrada, su nombre y nacionalidad, tener una familia y no ser separados de ella, el cuidado y amor, la educación y la cultura, la recreación y la libre expresión de su opinión. Serán protegidos contra toda forma de abandono, violencia física o moral, secuestro, venta, abuso sexual, explotación laboral o económica y trabajos riesgosos.

Gozarán también de los demás derechos consagrados en la Constitución, en las leyes y en los tratados internacionales ratificados por Colombia.

La familia, la sociedad y el Estado tienen la obligación de asistir y proteger al niño para garantizar su desarrollo armónico e integral y el ejercicio pleno de sus derechos. Cualquier persona puede exigir de la autoridad competente su cumplimiento y la sanción de los infractores.

Los derechos de los niños prevalecen sobre los derechos de los demás".

${ }^{13}$ Comité de Derechos del Niño (2016), párrafos 14 y 51. 
"Los Estados Partes pondrán el máximo empeño en garantizar el reconocimiento del principio de que ambos padres tienen obligaciones comunes en lo que respecta a la crianza y el desarrollo del niño. Incumbirá a los padres, o en su caso, a los representantes legales la responsabilidad primordial de la crianza y el desarrollo del niño. Su preocupación fundamental será el interés superior del niño".

Sin embargo, pese a que el derecho interno recoja las reglas internacionales sobre el respeto y protección a los NNA (por ejemplo, en el derecho de familia), consideramos que el trabajo de la Convención Constitucional que redacte la nueva Constitución de Chile será fundamental para alcanzar el reconocimiento expreso de los NNA como sujetos de derecho. Y también una fuente directa de los derechos fundamentales que poseen, y del deber que tienen tanto los padres como el Estado en su cuidado, crianza, protección y educación.

Cabe destacar que, si bien el estatuto internacional que marca la protección de los derechos de los NNA es la CDN, con anterioridad era posible encontrar algunos reconocimientos de principios protectores en otros tratados de derechos humanos. Así, en el Sistema Interamericano de Derechos Humanos se encuentra la DADH de la OEA de 1948. La Declaración prescribe la protección de la familia en el artículo sexto y reconoce la necesidad de otorgar protección a la mujer que se encuentre embarazada, así como a los niños en su artículo séptimo.

Dentro del mismo Sistema Interamericano, con mayor claridad que la DADH, se reconocerán algunos principios a favor de NNA y las relaciones entre los padres en la CADH de 1969. Tal como en la DADH, la $\mathrm{CADH}$ establece como un deber de los Estados otorgar protección a la familia en el art. 17.

A diferencia de la Declaración, la CADH desarrolla profusamente tal tutela. Así, en el número 4 del art. 17 señala que los Estados partes deben tomar medidas para asegurar la igualdad de derechos y la equivalencia de responsabilidad de los cónyuges durante el matrimonio y luego de disuelto. Agregando que se debe asegurar la protección de los hijos sobre la única base de su interés y conveniencia ${ }^{14}$. De tal forma, la CADH con anterioridad a la CDN estableció la necesidad de equivalencia de responsabilidades entre los cónyuges.

${ }^{14} \mathrm{El}$ art. 17 en su párrafo cuarto señala: "Los Estados Partes deben tomar medidas apropiadas para asegurar la igualdad de derechos y la adecuada equivalencia de responsabilidades de los cónyuges en cuanto al matrimonio, durante el matrimonio y en caso de disolución del mismo. En caso de disolución, se adoptarán disposiciones que aseguren la protección necesaria de los hijos, sobre la base única del interés y conveniencia de ellos". 
Lo que quisiéramos plantear en las próximas líneas es que el necesario reconocimiento constitucional de los NNA, recogiendo lo señalado por la normativa internacional, así como por las Constituciones comparadas, no solo será un avance en el ámbito social en tanto les reconocería derechos específicos, sino que tendrá repercusiones en el derecho privado, particularmente en el derecho de la responsabilidad civil de los padres por los daños ocasionados por sus hijos menores de edad.

\section{II. ¿CÓMO AFECTARÁ EN EL DERECHO CIVIL EL RECONOCIMIENTO CONSTITUCIONAL DE LOS NNA Y, ASIMISMO, EL PRINCIPIO DE CORRESPONSABILIDAD PARENTAL?}

Si bien es conocido que existe un proceso de constitucionalización del derecho civil, entendiendo por este la modificación por vía interpretativa de los preceptos civiles al aplicar directamente una norma constitucional o la reforma a la ley para adecuarla a la Constitución ${ }^{15}$, dicha situación no ha tenido lugar a propósito de la responsabilidad civil de los padres por el daño causado por sus hijos menores de edad. Esta situación se produce, en gran medida, porque la Constitución carece de una regulación aplicable que pudiera modificar los arts. 2319, 2320 y 2321 del Código Civil, más allá del derecho a la igualdad, y, además, porque la regulación establecida en los tratados internacionales de derechos humanos no ha permeado con la suficiente fuerza para modificar estos preceptos ${ }^{16}$.

Aquello resulta aún más problemático si observamos que tras la reforma legal al derecho de familia realizada el año 2013 mediante la Ley n. ${ }^{\circ} 20680$ se incluyó el principio de la corresponsabilidad parental, impactando en el cuidado personal y en la patria potestad, pero que no tuvo un correlato en todas las normas del Código Civil como lo son aquellas de la responsabilidad civil de los padres.

${ }^{15}$ Hernán Corral señala que la constitucionalización transcurre por diversas vías. En primer lugar, por la reforma legislativa; en segundo lugar, por la vía hermenéutica y, en tercer lugar, por la vía de la aplicación directa de la norma constitucional. CORRAL (2018b), p. 7 y ss. Lucio Pegoraro, por su parte sostiene: "Desde una perspectiva interna, la expresión 'constitucionalización del Derecho' tiene un sentido estricto: la interpretación tradicional es que la constitución permea cualquier rama del Derecho de cada ordenamiento: civil, penal, laboral, mercantil, financiero, etc., interpretados conforme al léxico y los 'valores' de la propia constitución". Pegoraro (2019), p. 45. Otros textos que lo exponen son: Corral (2014) y Fernández (2004).

${ }^{16}$ En Argentina, por ejemplo, se ha sostenido que la normativa vigente "demuestra un retraso en su adecuación a los nuevos tiempos presididos por las pautas fijadas por los Tratados Internacionales de los Derechos Humanos”. Alferillo (2013). 
En consecuencia, la corresponsabilidad que se regula en el Código Civil en el ámbito del derecho de familia, simplemente se abandona cuando se avanza a las normas de responsabilidad civil, en específico a la responsabilidad de los padres por el hecho de sus hijos ${ }^{17}$. Por ende, la consagración constitucional de los NNA, sus derechos y el principio de la corresponsabilidad parental importa una salida a estas contradicciones actuales del Código, lo que marcará un gran avance para nuestra sociedad ${ }^{18}$.

\section{Deberes de los padres respecto de sus hijos a la luz de la CDN}

Como hemos venido revisando, la posibilidad de incorporar en la nueva Constitución una referencia expresa a los derechos de NNA y también a la corresponsabilidad de los padres -como principales garantes de su protección y educación- no representa en ningún caso una idea revolucionaria, sino que, por el contrario, pareciera ser el piso mínimo necesario de abordar a la luz de los tratados internacionales que regulan la protección de los niños. Véase, por ejemplo, la Declaración de los Derechos de los Niños que data de 1959:

"El interés superior del niño debe ser el principio rector de quienes tienen la responsabilidad de su educación y orientación; dicha responsabilidad incumbe, en primer término, a sus padres"19.

${ }^{17}$ Pizarro (2017).

${ }^{18}$ Gutiérrez (2011) ha analizado la influencia de la Constitución española en el derecho civil, dando cuenta que este proceso se verifica varias veces por la consagración constitucional de normas propias del derecho civil, por ejemplo, la protección constitucional de la familia, los menores de edad o los consumidores.

${ }^{19}$ Principio n. ${ }^{\circ} 7$ Declaración de los Derechos del Niño. En un similar sentido, el año 1994 en la Conferencia Internacional sobre Población y el Desarrollo, El Cairo, Egipto se indicó como Principio 10. : "El interés del niño deberá ser el principio por el que se guíen los encargados de educarlo y orientarlo; esa responsabilidad incumbe ante todo a los padres". El Protocolo de San Salvador, por cierto, ha establecido en su art. 16 "Todo niño sea cual fuere su filiación tiene derecho a las medidas de protección que su condición de menor requiere por parte de su familia, de la sociedad y del Estado. Todo niño tiene el derecho de crecer al amparo y bajo la responsabilidad de sus padres; salvo circunstancias excepcionales, reconocidas judicialmente, el niño de corta edad no debe ser separado de su madre. Todo niño tiene derecho a la educación gratuita y obligatoria, al menos en su fase elemental, y a continuar su formación en niveles más elevados del sistema educativo". Sin ir más lejos, la CADH señala en su art. 17 que en caso de disolución del vínculo matrimonial "se adoptarán disposiciones que aseguren la protección necesaria de los hijos, sobre la base única del interés y conveniencia de ellos", reconociendo que se debe velar por su interés superior. 
Ahora bien, siguiendo la CDN, en ella es posible encontrar una serie de criterios que delimitan la responsabilidad de los padres. En tal sentido conviene destacar que la CDN, en su Preámbulo, señala como un principio fundamental la igualdad de todas las personas y que la familia como grupo fundamental de la sociedad debe recibir una protección especial. Enseguida, el art. 5 se refiere a la responsabilidad de los padres, la familia y la comunidad en la orientación de los NNA; el art. 9 de la CDN señala la obligación del Estado de evitar que se separen a los NNA de sus padres; el art. 14 consagra el deber de los Estados de respetar los derechos de los padres al guiar a los NNA en la libertad de pensamiento, conciencia y religión; el art. 18 establece, de forma muy concreta, que se debe garantizar la igualdad de obligaciones de los padres en la crianza y desarrollo de los NNA. Todas estas normas diagraman criterios claros que refieren a la responsabilidad de los padres respecto de sus hijos. Al respecto, Marcela Acuña reconoce en la $\mathrm{CDN}$ deberes de los padres, tanto de dirección y orientación como de crianza y desarrollo ${ }^{20}$. Como observamos, ambos deberes influyen directamente en la responsabilidad de los padres.

Una manifiesta relación de estos deberes puede expresarse en que las niñas y niños requieren de la guía de sus padres para aprender valores y normas comunes de comportamiento. En todo caso, en cumplimiento de su deber de dirección, los padres deben observar la autonomía progresiva de los niños, esto es, que sus hijas o hijos son personas independientes e irán adquiriendo la capacidad de ejercer de forma directa sus derechos, y de tal manera irán asumiendo progresivamente responsabilidades en reconocimiento de su autonomía ${ }^{21}$.

Por su parte, respecto al deber de crianza y desarrollo los padres deben asumir las obligaciones de alimentación, cuidado, asistencia y educación de sus hijos ${ }^{22}$. Esto implica que los padres deben asegurar que sus hijos

${ }^{20}$ ACUÑa (2020).

${ }^{21}$ Convención sobre los Derechos del Niño art. 5: "Los Estados Partes respetarán las responsabilidades, los derechos y los deberes de los padres o, en su caso, de los miembros de la familia ampliada o de la comunidad, según establezca la costumbre local, de los tutores u otras personas encargadas legalmente del niño de impartirle, en consonancia con la evolución de sus facultades, dirección y orientación apropiadas para que el niño ejerza los derechos reconocidos en la presente Convención”.

${ }^{22}$ En palabras de Jo Bridgeman: "Los niños, desde su nacimiento hasta la mayoría de edad, son inevitablemente dependientes de otros, físicamente, emocionalmente y económicamente. Si han de sobrevivir y desarrollarse, los niños requieren cuidados. Cuidar de, velar por y dar atención a un niño implica alimentarlo, vestirlo, proporcionarle un hogar, atenderlo cuando está enfermo, garantizar su tratamiento médico, tomar decisiones sobre su crianza, asegurar su educación, proporcionar orientación moral y disciplina, protegerlo del peligro, promover su bienestar físico y mental y promover su desarrollo social e intelectual”. BRIDGEMAN (2017). 
alcancen el desarrollo integral de sus personalidades ${ }^{23}$, debido a que la Convención recoge expresamente el principio de corresponsabilidad parental $^{24}$, que implica que ambos padres deberán asumir el cumplimiento de todos sus deberes para lograr el bienestar de los niños. Es más, en el caso de que un padre pierda, por ejemplo, el cuidado personal de su hijo, dicha circunstancia no lo eximirá de cumplir con sus obligaciones de desarrollo, crianza y orientación respecto de este ${ }^{25}$.

En suma, a partir de la CDN, el cuidado, dirección y crianza de los niños depende en primer término de sus padres. Estas son obligaciones comunes como claramente lo establece el art. 18 de la CDN, por lo que ambos padres deberán procurar el desarrollo y bienestar de sus hijos. Lo cual, en buena medida, implica que los padres tienen responsabilidad respecto de los actos que realicen sus hijos, al haberles orientado y educado de determinada manera. Esto permite sostener dos argumentos, por un lado, que las obligaciones son comunes, pues deben distribuirse de forma equilibrada entre ambos padres de modo que ninguno deba soportar una mayor carga en la crianza del NNA y, por otro, que se justifica en tanto el entorno adecuado en que debe desarrollarse el NNA es la familia ${ }^{26}$. de los padres en el Código CiVIL

Tomando en consideración lo expuesto, corresponde analizar la normativa del Código Civil sobre la responsabilidad civil de los padres por los daños causados por sus hijos. En primer lugar, debemos señalar que el art. 2320 incluye una presunción de culpa por el hecho ajeno, esto es, la obligación que tiene un tercero de responder por los daños que cause

${ }^{23}$ Cabe señalar que cuando hemos hecho referencia a los padres, nos referimos siempre a ambos.

${ }^{24}$ Convención sobre los Derechos del Niño, art. 18: "Los Estados Partes pondrán el máximo empeño en garantizar el reconocimiento del principio de que ambos padres tienen obligaciones comunes en lo que respecta a la crianza y el desarrollo del niño. Incumbirá a los padres o, en su caso, a los representantes legales la responsabilidad primordial de la crianza y el desarrollo del niño. Su preocupación fundamental será el interés superior del niño".

${ }^{25}$ ACUÑa (2020), pp. 123-124.

${ }^{26}$ Así se sostiene a lo largo de la CDN. Cabe destacar que el preámbulo de la CDN establece que la familia es el núcleo fundamental de la sociedad y el medio natural para el crecimiento y desarrollo del NNA. Asimismo, el preámbulo señala que el NNA para el desarrollo pleno y armonioso de su personalidad requiere crecer en el desarrollo de su familia. 
quien se encuentra bajo su vínculo de autoridad o cuidado ${ }^{27}$. Dicha norma no solo consagra una hipótesis general de este tipo de responsabilidad, sino que, también, situaciones específicas, siendo relevante, para efectos de este artículo, la consagrada en su inciso segundo, mediante la cual "el padre, y a falta de éste la madre, es responsable del hecho de los hijos menores que habiten en la misma casa”.

Las motivos o fundamentos de una responsabilidad por el hecho ajeno son, desde luego, conocidos, siendo el principal argumento la existencia de una relación de dependencia o la existencia de un vínculo de cuidado entre el agente directo del daño (en este caso el niño) y el tercero (los padres) que deben responder ${ }^{28}$.

De lo anterior, una pregunta relevante es si esta hipótesis de responsabilidad por el hecho ajeno podría verse modificada por una reforma constitucional que bien consagre los derechos de NNA, o que establezca en el ámbito de la carta fundamental principios del derecho de familia que actualmente solo se regulan bajo rango legal, como la corresponsabilidad de los padres en el cuidado de sus hijas e hijos ${ }^{29}$.

\section{Análisis del actual art. 2320 del Código Civil}

Desde el año 2013, mediante la promulgación de la Ley n. ${ }^{\circ} 20680$ se modifica un importante aspecto del derecho de familia chileno, dado que se reconoce el principio de corresponsabilidad parental, dejando atrás el obsoleto art. 225 del Código Civil que indicaba: "Si los padres viven separados, a la madre toca el cuidado personal de los hijos".

${ }^{27}$ Barros (2020), p. 173 y ss.

${ }^{28}$ Así, por ejemplo, LÓPEz dE LA CRUZ (2013) ha sostenido: "Es preciso tener en cuenta que la responsabilidad civil de los padres dimanante de los actos ilícitos ejecutados por los hijos constituidos 'in postestate', a tenor del citado precepto artículo 1903, inciso segundo del Código Civil español, se justifica tradicional y doctrinalmente por la transgresión del deber de vigilancia que a los primeros incumbe, omisión de la obligada diligencia 'in custodiendo' o 'in vigilando' que el legislador contempla partiendo de la presunción de culpa concurrente en quien desempeña los poderes y deberes integrantes de la patria potestad [...]”. En sentido análogo Barros (2020), p. 173 y ss.; Corral (2013), p. 231 y ss.

${ }^{29}$ Bonilla (2009), p. 66: "Se debe tener en cuenta no sólo el análisis del ordenamiento jurídico en materia de daños, de responsabilidad, sino que junto a éste ha de analizarse la normativa relacionada con el Derecho de familia, puesto que al existir un vínculo familiar entre el autor material del hecho y la persona llamada a responder, padre, tutor, etc., se debe considerar, igualmente, si ha de existir una cierta coherencia entre la configuración del Derecho de familia y esta responsabilidad por hecho ajeno o, por el contrario, pueden discurrir de forma independiente". 
Con aquella modificación legal podríamos pensar que el art. 2320 del Código Civil habría quedado derogado. Pero tal como han señalado ciertos autores $^{30}$, mientras no exista una derogación expresa al art. 2320, la regla continuaría de la siguiente forma:

"Toda persona es responsable no sólo de sus propias acciones, sino del hecho de aquellos que estuvieren a su cuidado.

Así el padre, y a falta de éste la madre, es responsable del hecho de los hijos menores que habiten en la misma casa [...]. Pero cesará la obligación de esas personas si con la autoridad y el cuidado que su respectiva calidad les confiere y prescribe, no hubieren podido impedir el hecho" ${ }^{31}$.

Los criterios entonces son, primero, la subsidiariedad del responsable, esto es, que responda el padre de los hechos de aquellos que estuvieren bajo su cuidado, y a falta del padre, la madre. En segundo lugar, la habitabilidad de los hijos con sus padres.

No es posible olvidar que dicha norma tiene su origen en el derecho romano, donde el padre era el único que tenía la autoridad para responder por el hecho de sus dependientes, en este caso, de sus hijos. Sin embargo, la importancia de su reforma quedó demostrada al haberse utilizado aquel criterio subsidiario en un fallo de la Corte Suprema de 5 de julio de 2018, en el que se condenó civilmente al padre y no a la madre de un niño que habría provocado un caso de cyberbullying contra otra niña ${ }^{32}$.

Ahora bien, pese a que el análisis de la responsabilidad por el hecho ajeno se ha abordado con frecuencia por la doctrina ${ }^{33}$, son pocas las menciones a la regulación de la responsabilidad en el caso de los padres ${ }^{34}$. Desde luego, se trata de una regulación anacrónica que solo responde al origen romano de la regla en que el padre debía responder por los hechos de los hijos y que, entonces, recoge una responsabilidad subsidiaria de la madre.

Por otra parte, en regulaciones de otras naciones no solo existen normas generales de responsabilidad por el hecho ajeno, sino que, también, se consagran hipótesis específicas de la responsabilidad de los padres. Así, por ejemplo, en Francia el art. 1242 del Code señala:

${ }^{30}$ Contardo (2020).

${ }^{31} \mathrm{El}$ destacado es nuestro.

${ }^{32}$ D. C. J. A. y otro con P. U. C. A. y otra (2017).

${ }^{33}$ Véase Barros (2020); Corral (2013); Meza (2009) y Alessandri (2005).

${ }^{34}$ Rizik (2018); Rizik (2016); San Martín (2016a); San Martín (2016b); Mendoza (2019); Pizarro (2017) y Tovani (2012). 
"El padre y la madre, en la medida que ejercen la patria potestad, son solidariamente responsables del daño causado por los hijos menores que vivan con ellos"35.

En España el inciso segundo del art. 1903 del Código Civil establece: "Los padres son responsables de los daños causados por los hijos que se encuentren bajo su guarda”. También en el reciente Código Civily Comercial Argentino se regula esta responsabilidad en su art. 1754 en los siguientes términos:

"Los padres son solidariamente responsables por los daños causados por los hijos que se encuentran bajo su responsabilidad parental y que habitan con ellos, sin perjuicio de la responsabilidad personal y concurrente que pueda caber a los hijos".

Es más, las modernas regulaciones de este tipo de responsabilidad distan de la chilena. Así, por ejemplo, los Principios de Derecho Europeo de la Responsabilidad Civil se refieren a la "responsabilidad por otros":

"La persona que tiene a su cargo otra persona que es menor o sufre discapacidad psíquica responde por el daño causado por esa otra persona a menos que demuestre que ella misma cumplió con el estándar de conducta que le era exigible en su supervisión”36.

Como apreciamos, los Códigos Civiles no se quedan tan solo en la regulación general de la responsabilidad por el hecho ajeno, sino que consagran hipótesis específicas en que los padres responden por los hechos ilícitos cometidos por sus hijos. En algunos casos, no existirá un calificativo para esa responsabilidad de los padres, como es el caso español, en que a simple vista pareciera ser que los padres responderán de forma conjunta o, en otros, como el caso francés y argentino, esa responsabilidad será solidaria, debiendo soportar ambos o cualquiera el total de la indemnización por el daño causado por el niño o niña. Todas esas hipótesis difieren de la consagrada en nuestra legislación. Así, como hemos señalado, la atribución de responsabilidad por el hecho del menor será soportada en primer lugar por el padre y, solo a falta de este, por la madre.

${ }^{35}$ Art. 1242. "Le père et la mère, en tant qu'ils exercent l'autorité parentale, sont solidairement responsables du dommage causé par leurs enfants mineurs habitant avec eux". (La traducción es nuestra).

${ }^{36}$ Capítulo 6, art. 6: 101 referido a "responsabilidad por los menores o por discapacitados psíquicos". 
Cabe preguntarse entonces, ¿̇la consagración constitucional de la corresponsabilidad parental puede incidir en la responsabilidad civil? Si bien no existe una respuesta clara, podemos evaluar cómo la reforma en esa materia podría obligar a adaptar la regulación. La actual norma de responsabilidad por el hecho de los hijos menores data del origen del Código Civily, como hemos indicado, no tuvo en consideración la reforma del año 2013 a la patria potestad en materia de familia. En este aspecto, creemos que la norma legal debiera adaptarse según la corresponsabilidad parental que se regule en el ámbito constitucional. Si la Constitución estableciera como derecho de los NNA que sus padres le entreguen una educación adecuada o que, además, sus padres serán corresponsables en su cuidado (así como en otros deberes), entonces el Código Civil-respetando la jerarquía normativa de la Constitución en el ordenamiento jurídico- tendría que reflejar aquel cambio en su articulado.

En ese sentido, la actual responsabilidad subsidiaria de los padres se encontraría injustificada. En otros términos, ¿̇ué fundamento podría mantener un criterio de subsidiariedad ante una corresponsabilidad de ambos padres en el cuidado, educación y crianza de los hijos menores de edad?

Si una nueva Constitución consagrara la corresponsabilidad parental, 196 o establece disposiciones a favor de los NNA o de los hijos menores de edad de forma similar a las Constituciones a las que se hizo mención o a la CDN, entonces la norma del Código Civil no solo se mantendría desactualizada a los tiempos actuales, sino que adolecería de un vicio de constitucionalidad.

La influencia de la Constitución en la regulación en general y en la regulación civil en particular es evidente, y hay varios ejemplos en los que se puede apreciar. Primero, el principio de igualdad, el derecho a la no discriminación o, incluso, la protección a la propiedad han llevado a la intervención judicial de varias instituciones civiles por distintas vías (a través del recurso de protección, del Tribunal Constitucional o de la aplicación por los jueces de letras de la normativa constitucional). Piénsese, por ejemplo, el reconocimiento a derechos de género por vía judicial mediante rectificaciones de partidas de nacimiento previo a la dictación de la Ley de Identidad de Género, la inaplicabilidad de la conducta homosexual como causal de divorcio culpable o el reconocimiento judicial de una familia homoparental al establecer a dos mujeres como madres en la partida de nacimiento ${ }^{37}$ de un hijo, entre muchos otros aspectos. Pero

${ }^{37}$ Así lo resolvió el segundo juzgado de familia de Santiago en sentencia del año 2020. Véase www.diarioconstitucional.cl/2020/06/08/juzgado-de-familia-acoge-demanda-ydeclara-que-nino-de-2-anos-es-hijo-de-dos-mujeres/ [fecha de consulta: 20 de mayo 2021]. 
ese avance pretoriano en materia de familia no se ha visto reflejado en ningún caso en la responsabilidad civil.

Tomando en consideración lo señalado, queremos esbozar ciertas directrices para que la responsabilidad por el hecho de los hijos e hijas menores de edad se encuentre en afinidad con una regulación constitucional similar a la comparada o adecuada a los tratados internacionales ya vigentes.

\section{CRiterios PARA MODIFICAR LA NORMATIVA ACTUAL}

A partir de lo abordado, quisiéramos ofrecer dos criterios que podrían reemplazar los elementos principales del actual art. 2320, a saber: la subsidiariedad y la habitabilidad con los padres. A continuación, proponemos que la nueva regulación civil tome en consideración tanto la corresponsabilidad parental como la autonomía progresiva del niño o niña.

\section{Corresponsabilidad parental}

Los tratados internacionales reconocen la corresponsabilidad parental, esto es, el reparto equitativo de los derechos y deberes de los padres respecto de sus hijos ${ }^{38}$, como un principio que debe implementarse en la crianza, educación y guía de las hijas e hijos ${ }^{39}$. Entonces, si una norma constitucional diera reconocimiento a este principio, ya sea mediante el establecimiento de la aplicación directa de los tratados internacionales con un rango superior al legal o, bien, si la Constitución reconoce y consagra los derechos de los NNA o los principios del derecho de familia a su favor, estimamos que eso se debe ver clara y directamente reflejado en la norma de responsabilidad por el hecho ajeno.

De esta forma, una responsabilidad por el hecho ajeno referida a la responsabilidad de los padres por los hechos cometidos por sus hijos menores de edad, deberá tomar en consideración la corresponsabilidad que entre ambos padres debe existir respecto de la crianza, educación, promoción de los derechos y desarrollo personal de la hija o hijo ${ }^{40}$.

${ }^{38}$ ACUÑa (2013), p. 28. En igual sentido Lathrop (2008), p. 22.

${ }^{39}$ ACUÑa (2013), p. 24 y ss. La autora señala que la corresponsabilidad se encontraría consagrada en la propia declaración universal de derechos humanos, en el Pacto Internacional de Derechos Civiles y Políticos promulgado en Chile en 1989 y en la Convención Americana sobre Derechos Humanos, al reconocer la igualdad de los cónyuges dentro del matrimonio y la igualdad de derechos y responsabilidad de los padres.

${ }^{40}$ Tovani (2012), p. 258. Ha sostenido que "el fundamento de los dos tipos de responsabilidad [objetiva o subjetiva respecto de los hechos de los hijos] es el mismo: el hecho biológico de la paternidad implica una responsabilidad hacia los niños y hacia los terceros". 
Esta situación debiera plantear una seria modificación a nuestra norma de responsabilidad civil, pues el compartir los derechos y deberes respecto de los hijos precisa un correlato en la responsabilidad civil cuando se trate de hacerlos responsables. En primer lugar, carecería de sentido una norma de responsabilidad subsidiaria como la actual, en que la responsabilidad recae de forma principal en el padre, y a falta de este, en la madre. Como hemos visto, dicha norma ya se encuentra desajustada con la normativa de familia de la patria potestad y del cuidado personal ${ }^{41}$, pero más aún lo estaría con una normativa constitucional que recogiera el deber de ambos padres de preocuparse y promover la educación de los hijos, que derivare, entonces, en una responsabilidad coparental.

Por otra parte, la redacción de la norma actual cuenta con una raigambre claramente patriarcal ${ }^{42}$, que atribuye la responsabilidad en el padre y, solo a falta de este, en la madre. En todo caso, aquella atribución requiere cumplir con otro factor normativo como es la habitabilidad ${ }^{43}$. Así, no basta con que el NNA cometa un ilícito civil para atribuir la responsabilidad al padre, sino que se requiere que exista un vínculo de habitabilidad entre el NNA y el padre. Al respecto se requiere tener en cuenta que una gran

${ }^{41}$ Pizarro (2017). "Otra crítica que puede hacerse al precepto es la preeminencia que otorga al padre y sólo a falta de éste asume la responsabilidad la madre, lo que no se condice con las reglas ya vistas a propósito del cuidado personal".

${ }^{42}$ Por lo demás, una obligación del Estado chileno, al ratificar el año 1989 la CEDAW, es adoptar todas las medidas adecuadas para eliminar la discriminación contra la mujer en todos los asuntos relacionados con el matrimonio y las relaciones familiares y, en particular, asegurar condiciones de igualdad entre hombres y mujeres en los mismos derechos y responsabilidades como progenitores, cualquiera sea su estado civil en materias relacionadas con sus hijos; en todos los casos, los intereses de los hijos serán la consideración primordial, según indica el artículo 16 letra d) de la CEDAW. Al respecto, el Comité para la Eliminación de la Discriminación contra la Mujer estableció en su recomendación general n. 21 del año 1994 que: "Los Estados Partes deberían velar porque conforme a sus leyes, ambos padres, sin tener en cuenta su estado civil o si viven con sus hijos, compartan los derechos y las obligaciones con respecto a ellos en pie de igualdad". También sostuvo en su recomendación general n. ${ }^{\circ} 29$ de 2013: “[...] El examen de los informes de los Estados partes revela que en muchos Estados los derechos y responsabilidades de los cónyuges se rigen por los principios del derecho civil o común, por leyes y prácticas religiosas o consuetudinarias o por alguna combinación de esas leyes y prácticas que discriminan a la mujer y no cumplen los principios establecidos en la Convención”.

${ }^{43} \mathrm{Al}$ respecto, Pizarro (2017), pp. 112-226, ha sostenido: "El criterio de habitabilidad ha sido criticado en la aplicación de la norma, pues genera problemas de determinación de la responsabilidad civil cuando los agentes directos del daño se encuentran fuera de su hogar. En la actualidad esta disposición no está exenta de crítica, si consideramos que la 'habitabilidad' constituye un elemento relativo dada la movilidad que puede tener el niño a la edad en que resulta aplicable el precepto. En el caso francés, por ejemplo, se ha extendido este criterio objetivo a situaciones en que el hijo se encuentra en casa de parientes por un período o en vacaciones alejado de la residencia de sus padres". 
parte de los hogares de nuestro país son monoparentales, recayendo en la mayoría de los casos el cuidado personal sobre la madre. En consecuencia, la norma actual incluso podría llevar a un resultado contrario al originalmente pensado, pues el criterio de habitabilidad no terminaría sino por atribuir la responsabilidad en la madre como tercera civilmente responsable, traduciéndose otra vez en una norma discriminatoria contra la mujer.

Respecto a lo último, la CIDH ha puesto énfasis en que según el art. 18 de la CDN, los Estados pondrán el máximo empeño en garantizar que ambos padres tienen obligaciones comunes en lo que respecta a la crianza y desarrollo del niño. Y en el mismo sentido la Corte ha indicado que se deben erradicar estereotipos de género que, por ejemplo, atribuyan a las mujeres el papel social de madres con ideas preconcebidas según el cual debieran llevar una responsabilidad principal en la crianza de sus hijos. Así lo muestra este esclarecedor considerando del caso R. E. y otros vs. Guatemala ${ }^{44}$ :

"Ahora bien, esta asignación de roles no solo actuó en perjuicio de la señora R. E., sino también del señor T. F. Nunca se intentó ni consideró ubicar a G. T. F, padre de O. T. R., para investigar la posibilidad de concederle el cuidado de su hijo. Como mencionó el señor Tobar Ramírez, si bien vivía en otro país, él mantenía una relación familiar con su hijo y no había desatendido sus responsabilidades con respecto a O. T. R. Una vez enterado de lo sucedido, el señor T. F. [...] intentó por todos los medios legales a su alcance recuperar a su hijo y al hermano de éste, a pesar de que las diferentes autoridades legales que intervinieron en el caso jamás lo consideraron al separar a su hijo de su familia, entregarlo en adopción internacional y removerlo del país. Por tanto, en este caso los estereotipos sobre la distribución de roles parentales no solo se basaron en una idea preconcebida sobre el rol de la madre, sino también en un estereotipo machista sobre el rol del padre que asignó nulo valor al afecto y cuidado que el señor T. F. podía ofrecer a O. T. R. como su padre. De esta manera, se privó al señor T. F. de sus derechos parentales, en cierta medida presumiendo e insinuando que un padre no tiene las

${ }^{44}$ R. E. y otros vs. Guatemala (2018). El caso se funda en que dos hermanos O. T. R. y J. R, son internados en la Asociación Los Niños de Guatemala luego de una denuncia anónima que indicaba el supuesto abandono de la madre. Luego de ser retirados de su hogar, su madre acude al juzgado de menores y no se le permitió verlos. Se concedió la tutela legal de los niños a dicha Asociación y en menos de un año fueron incluidos en un programa de adopción internacional. Ambos niños fueron adoptados por familias distintas de Estados Unidos en 1998. Ese mismo año, el padre de O. T. presentó un recurso de revisión. Sin embargo, con fecha 2002 se archivó de manera definitiva el caso, porque el señor T. F. no había pagado los gastos de notificación a los padres de los niños en Estados Unidos. 
mismas obligaciones o derechos que una madre, ni el mismo interés, amor y capacidad para brindar cuidado y protección a sus hijos" ${ }^{45}$.

En el mismo sentido, el Comité para la Eliminación de la Discriminación contra la Mujer ha indicado en sus últimas observaciones al Informe del Estado Chileno de 2018:

"Sigue preocupado porque los persistentes estereotipos discriminatorios sobre las funciones y las responsabilidades de las mujeres y hombres en la familia [...] siguen impidiendo los progresos en la promoción de la igualdad de género" ${ }^{46}$.

Por otra parte, el desajuste de la normativa resulta evidente puesto que tampoco contempla una fase de distribución de la deuda entre ambos padres, o de contribución a la deuda si pensáramos en términos de solidaridad. Así, los supuestos que se pueden pensar son aquellos en que el hijo habita solo con el padre; que habita con ambos padres; que habita solo con la madre y, finalmente, una en que vive con un tercero. En los casos en que habitara con el padre o con ambos padres, la indemnización deberá ser soportada por el padre y, si los bienes no fueran suficientes, por la madre. Luego, si vive solo con la madre, la indemnización solo recaería en ella. 200 Como apreciamos, tampoco existe una regla que distribuya la indemnización entre ambos padres una vez solventada por uno de ellos, pues siempre deberá ser soportada en la forma dispuesta en la cadena: si el padre paga solo la soporta él, si no es suficiente la soportará con sus bienes y enseguida con los de la madre y, finalmente, si no hay padre solo lo soportará la madre, careciendo de una regulación que distribuya en equidad la indemnización sobre ambos (sin perjuicio del derecho a repetir consagrado en el art. 2325, en contra del hijo). La norma, otra vez desde esta óptica, carece de igualdad entre los progenitores ${ }^{47}$.

Acorde con la regulación internacional ${ }^{48}$ y constitucional ${ }^{49}$-sin ir más lejos, al principio o derecho a la igualdad-, la norma debiera atribuir la responsabilidad en ambos padres, tomando en cuenta que la función de ellos es promover el desarrollo integral tanto educacional como social del NNA. En particular, al considerar al NNA como un sujeto de derecho, la atención que se le dedique en virtud de su vulnerabilidad frente a adultos plenamente capaces -como lo son sus dos padres- debe implicar que, si el NNA comete un ilícito civil, ello podría ser indiciario de una negligencia de los padres en la promoción

\footnotetext{
${ }^{45}$ R. E. y otros vs. Guatemala (20018), considerando 298 (énfasis agregado).

${ }^{46}$ Comité para la Eliminación de la Discriminación contra la Mujer (2018).

${ }^{47}$ Mendoza (2019).

${ }^{48}$ Art. 18 n. ${ }^{\circ} 1$ de la CDN; art. 27 n. ${ }^{\circ} 2$ de la CDN; art. 16 letra d) de la CEDAW.

${ }^{49}$ Art. 19 n. ${ }^{\circ} 2$ de la Constitución Política de la República de Chile.
} 
de su desarrollo, su crianza o en el cuidado que deben darle. Vale la pena recordar que el fundamento tradicional de esta hipótesis de responsabilidad por el hecho ajeno es haber fallado en la vigilancia, educación y crianza del hijo menor de edad, lo que justifica atribuir en los padres la responsabilidad.

El aspecto anterior implica mirar a ambos padres como responsables del desarrollo del NNA, y no colocar la carga sobre tan solo uno de ellos ${ }^{50}$. En ese entendido, no parecería apropiada una norma de responsabilidad que la atribuye sobre quien tiene la patria potestad o el cuidado personal, pues con ello se terminaría imponiendo mayores cargas sobre el padre o madre (y, por la composición de nuestra sociedad probablemente sobre esta) que tenga al NNA a su cuidado, desligando de responsabilidad al otro progenitor que puede que tenga una menor o nula presencia o injerencia en el desarrollo del NNA, lo cual importa un claro ejemplo de la falta de observancia a sus deberes como madre o padre ${ }^{51}$.

Además, tal como alguna doctrina lo ha señalado ${ }^{52}$, ni siquiera el criterio de la habitabilidad debiera ser determinante en la responsabilidad de los progenitores respectos de sus hijas o hijos menores de edad. Esto, toda vez que la misma normativa de derecho de familia permite un cuidado personal compartido en casos en que tan solo uno habite con el menor de edad, tomando en cuenta el interés superior del niño para garantizar su estabilidad emocional. Por cierto, el objetivo es que ambos padres participen en la crianza y educación del hijo o hija, con independencia del lugar de residencia de este o esta. Aquello impone como contrapartida que en los casos que deba atribuirse responsabilidad por los daños que causen, dicha indemnización ha de ser soportada por ambos padres.

De forma clásica y tradicional se ha sostenido que la atribución de responsabilidad en los padres es in vigilando e in educando ${ }^{53}$, justificándose

${ }^{50}$ La CEDAW, adoptada por la Asamblea General de las Naciones Unidas el 18 de diciembre de 1979, dispone en su art. 5 letra b) que los Estados parte tomarán las medidas apropiadas para "Garantizar que la educación familiar incluya una comprensión adecuada de la maternidad como función social y el reconocimiento de la responsabilidad común de hombres y mujeres en cuanto a la educación y al desarrollo de sus hijos, en la inteligencia de que el interés de los hijos constituirá la consideración primordial en todos los casos", reafirmando esta responsabilidad compartida en la educación y desarrollo de los hijos.

${ }^{51}$ Respecto a este punto, conviene recordar la resolución de la Corte Suprema en reservado (2014), la cual indica: "El aporte dinerario no es suficiente para estimar que se ha velado por la crianza, cuidado personal o educación del hijo. Velar por el bienestar de un hijo implica una serie de elementos que van todos dirigidos a permitir que tenga la posibilidad de tener un desarrollo íntegro de su vida”.

${ }^{52}$ Rizik (2021), p. 44.

${ }^{53} \mathrm{Su}$ fundamento sería la atribución del deber de velar por los hijos que se encuentran bajo la guarda, conllevando el deber de control y vigilancia. De ahí se derivaría que los menores de edad no deben lesionar intereses ajenos. Bonilla (2009), p. 70. 
que respondan porque no han empleado el cuidado o la vigilancia debida para evitar que su hija o hijo cometa hechos ilícitos. La norma no contempla el principio de protección del interés superior del niño, situación que debiera ser enmendada por los mismos fundamentos que hemos expresado. En tal sentido, una solución podría ser que los deberes de los padres apunten siempre en beneficio de salvaguardar dicho interés.

Esto permitiría dotar de contenido al elemento de la imputación subjetiva de los padres en la responsabilidad, al vincular la diligencia o negligencia con el directo cumplimiento de los deberes filiativos maternos y paternos. La responsabilidad del tercero civilmente responsable debe tener en consideración el aporte que cada padre ha realizado en pos de favorecer tal interés, el cumplimiento de sus deberes ${ }^{54}$ y la satisfacción u observancia del interés superior del NNA. Así, en la medida que el padre o la madre no pueda acreditar su diligencia, en el sentido de haber realizado los esfuerzos necesarios para colocar en el centro el interés superior del NNA cumpliendo sus deberes que derivan del derecho de familia, no podrá exonerarse de la culpa en su actuar ${ }^{55}$. Aquello permitiría agregar mayores exigencias de responsabilidad parental, pues entendida

${ }^{54}$ Chile carece de normas que atribuyan responsabilidad parental en el derecho de familia, a diferencia de otros países como Argentina, que han detallado el contenido de la responsabilidad parental. LATHROP (2017).

${ }_{55}$ Aproximaciones a esta idea se observan en Pizarro (2017).

Se debe tener en cuenta que el interés superior del niño se consagra explícitamente en el art. 3 de la CDN. A su respecto, en la observación general n. ${ }^{\circ}$ 14, el Comité de Derechos del Niño ha señalado que el interés superior del niño obliga a observar sus derechos siempre buscando la primacía del interés del NNA. En tal sentido ha indicado que la CDN "otorga al niño el derecho a que se considere y tenga en cuenta de manera primordial su interés superior en todas las medidas o decisiones que le afecten, tanto en la esfera pública como en la privada”. Comité de Derechos del Niño (2013), p. 2.

También se ha sostenido: "Las críticas a ambos criterios [responsabilidad in vigilando e in educando] han hecho que se busquen otros, entre los que se incluye la infracción de los deberes de la patria potestad. La obligación de indemnizar no surge tanto como consecuencia de la culpa in vigilando o in educando, cuanto por entender que entre los deberes que tienen los padres para con los hijos se encuentran el que estos últimos no causen un daño a terceros. Precisamente, la producción de ese daño hace que surja la obligación de responder". Bonilla (2009), p. 73. Si bien el autor da cuenta del tránsito desde los criterios clásicos hacia los deberes de la patria potestad, señala que entre estos se incluiría el deber de evitar que los menores de edad produzcan daños a terceros, lo que sería diferente a acreditar el incumplimiento del deber de vigilar. En este aspecto, atribuir la responsabilidad en el deber general de no causar daño a otro como un deber derivado de la patria potestad no realiza mayores aportes, pues acreditados los requisitos de la responsabilidad respecto del agente directo del daño, se tendrá por acreditado que afectó el deber de no dañar a otro, transformándose derechamente en una responsabilidad objetiva. Más bien, estimamos que debe ser la observancia o inobservancia de específicos deberes filiativos lo que justifique la atribución de responsabilidad en el tercero. 
así la atribución de responsabilidad en el tercero, aun cuando se trate de una labor conjunta, el padre o madre que desatendió sus obligaciones para con el NNA, deberá soportar en mayor medida o en su totalidad la indemnización por el hecho ilícito.

Con todo, y por no ser el objeto de este trabajo, no nos referiremos a si la atribución de responsabilidad en ambos padres deberá ser solidaria o simplemente conjunta, pero de todas formas aquella decisión debe observar el nivel de garantía que se quiera entregar a la víctima del daño, así como la relación entre los obligados a la deuda como terceros civilmente responsables (los padres) ${ }^{56}$. Sea cual sea el régimen por el cual se opte, creemos que debe tomar en consideración las continuas discriminaciones que se han producido en el derecho de familia ${ }^{57}$, de modo tal que no sean las mujeres las que terminen por soportar o tener que cumplir con una mayor carga indemnizatoria.

En definitiva, en el ámbito de contribución a la deuda entre los padres, podría ser necesario que la norma indique criterios orientadores al operador jurídico para determinar en qué medida cada uno soportará la indemnización, tales como la capacidad económica de cada uno, los gastos de crianza o educación o la medida que cada uno ha soportado, o su participación en otorgar orientación y cuidado adecuado al NNA, así como a su desarrollo integral. Dichos criterios permitirían cumplir con normas constitucionales que prohíben la discriminación contra la mujer por respeto a la igualdad, posiblemente atribuyendo responsabilidad por los daños al padre que estuvo ausente y no al que fue diligente y se preocupó del desarrollo del hijo o hija.

${ }^{56}$ La decisión sobre si los padres deben responder de forma solidaria o simplemente conjunta tiene una serie de consecuencias. En primer lugar, desde el punto de vista de la víctima del daño, la solidaridad de los padres implica una mayor garantía, pues habrá más patrimonios en los que pueda buscar la indemnización. En segundo lugar, desde el punto de vista de los padres, creemos que la decisión puede incidir, incluso, en la prueba de su diligencia. Conviene explicar de forma somera este punto. Si la responsabilidad de los padres es solidaria, el cumplimiento de los deberes será observado de forma conjunta. No cabría en esta hipótesis la opción que el padre o madre diligente pueda probar su diligencia particular y quedar excusado de responder, ya que en el caso que uno haya sido negligente, es probable que no sea posible liberarse de la presunción de culpa. Deberían ambos probar su diligencia para romper el vínculo. Por un lado, esto puede llevar al padre o madre diligente a soportar la indemnización en la fase de obligación a la deuda, y solo en la fase de contribución a la deuda repetir contra el padre negligente. Por otro, parece ser que la integración de la solidaridad permite que exista una preocupación conjunta mayor, que es la forma en que estimamos se debe ejercer la responsabilidad parental. Por último, la decisión de una responsabilidad simplemente conjunta adelantaría la discusión de la diligencia entre los padres, pues ambos querrían demostrarla para quedar exonerados de responder. Así, el que acredite diligencia no debería soportar la indemnización.

${ }^{57}$ Albornoz (2021), p. 70. 


\section{Autonomía y desarrollo progresivo del NNA}

Según lo revisado en algunas constituciones y también se observa en la CDN, las normativas internas de los países deben adecuarse al desarrollo progresivo y la autonomía que van adquiriendo los NNA ${ }^{58}$. Así, la educación y crianza entregada por los padres no puede obviar la autonomía que van adquiriendo los NNA a medida que van creciendo. Esto implica que quienes tienen a su cuidado a un NNA deberán ser más cuidadosos en las etapas iniciales de su vida, pero deberán ir otorgando mayor libertad a medida que se van desarrollando ${ }^{59}$.

Recientemente la CIDH analizó en el caso G. A. y otras vs. Ecuador ${ }^{60}$, la importancia de conceder a los NNA las herramientas, tales como la educación sexual, para que los niños puedan gozar de una verdadera autonomía para tomar decisiones, por ejemplo, sobre su sexualidad. En el referido caso, la Corte identifica con claridad que la violencia come-

${ }^{58}$ De acuerdo con la CDN el art. 12 consagra el derecho del niño a expresar su opinión de forma libre en todos los asuntos que le afecten, teniendo en cuenta sus opiniones, en función de su edad y madurez. Asimismo, el art. $3 .^{\circ}$ señala que todas las instituciones públicas y privadas deberán tener una consideración primordial en el interés superior 204 del niño. Por su parte, el art. 2. ${ }^{\circ}$ de la Convención establece que todo niño tiene derecho a no ser discriminado en el ejercicio de sus derechos. Junto con los artículos precedentes, el Comité de los Derechos del NiÑo (2009), indicó que los arts. 13 y 17 de la CDN son fundamentales para lograr el efectivo derecho a ser escuchado, dado que con el derecho a la libertad de expresión del art. 13 y el derecho a acceder a información que contempla el art. 17, será posible afirmar que el niño tiene derecho a ejercer esos derechos en su propio nombre conforme a la evolución de sus facultades.

${ }^{59}$ Bonilla (2009), p. 70 y ss. ha indicado: "En lo concerniente a la relación entre la edad del menor y el deber de control, hay que decir que no es el mismo control el que debe ejercerse sobre una persona que tenga una muy corta edad, que el control al que debe someterse a un individuo de edad próxima a la mayoría de edad, pese a que en ambos supuestos nos encontremos ante menores de edad. En el primer caso, el deber de vigilancia y control se encuentra más acentuado; pero el criterio del control o vigilancia comienza a diluirse cuando el sujeto va cumpliendo años, de tal manera que sí que es posible distinguir entre los niños de corta edad de aquellos otros denominados 'los grandes menores', individuos próximos al cumplimiento de la mayoría de edad".

${ }^{60} \mathrm{El}$ caso G. A. y otras vs. Ecuador (2020) se funda en los siguientes hechos, la víctima P. G. A. de entonces catorce años de edad, sufrió abusos y violaciones reiteradas por parte del Vicerrector del colegio al que asistía, quien le ofreció pasarla de año con la condición de mantener relaciones sexuales con él. Esta situación persistió hasta que ella cumplió los dieciséis años. Dos días después de su cumpleaños la víctima se suicidó dejando tres cartas. La Corte condenó al Estado de Ecuador, ordenándole implementar medidas para corregir la deficiencia en el ámbito educativo relacionadas a la violencia sexual, a capacitar al personal del ámbito educativo, a orientar y entregar asistencia a la víctimas de violencia sexual en el ámbito educativo, a declarar un día oficial de lucha contra la violencia sexual en las aulas, entre otras. 
tida contra la adolescente fue en un contexto de abuso de poder, en el cual la persona que estaba al cuidado de ella, aprovechó la posición de vulnerabilidad de la víctima para consumar los actos de violencia sexual en su contra. Así, la Corte sostuvo:

"La educación debe ser apta para posibilitar a las niñas y los niños un adecuado entendimiento de las implicancias de las relaciones sexuales y afectivas, particularmente en relación con el consentimiento y el ejercicio de las libertades respecto a sus derechos sexuales y reproductivos" ${ }^{\prime 6}$.

En consecuencia, a partir del caso se puede extraer que debe promoverse la educación e información que favorezca el respeto a la autonomía progresiva de los NNA, sin dejar de lado las medidas de protección que los resguardan de un eventual menoscabo a sus derechos, en aprovechamiento de su vulnerabilidad.

Por su parte, el Comité de Derechos del Niño, ha señalado que el Interés Superior del Niño es primordial ante cualquier medida concerniente a los NNA, como sería la responsabilidad derivada de sus actos. En tal sentido la observación general n. ${ }^{\circ} 7$ del Comité señala:

"El principio de interés superior del niño se aplica a todas las medidas que afecten a los niños y exige medidas activas, tanto para proteger sus derechos y promover su supervivencia, crecimiento y bienestar como para apoyar y asistir a los padres y a otras personas que tengan la responsabilidad cotidiana de la realización de los derechos del niño" ${ }^{62}$.

En ese sentido cabe preguntarnos si reconocer el desarrollo progresivo en el ámbito constitucional requiere una modificación a la norma de responsabilidad por el hecho de los hijos. Estimamos que la respuesta no solo es afirmativa, sino que implica una revisión de las tres normas de la responsabilidad extracontractual por el hecho de los hijos, a saber: los arts. 2319, 2320 y 2321.

El actual sistema de responsabilidad por el hecho de los hijos menores de edad distingue la responsabilidad en el caso de los incapaces absolutos, hipótesis en la que los padres serán responsables si se les atribuye negligencia. En segundo lugar, la situación de los menores de edad mayores de dieciséis años, pero que aún no han cumplido dieciocho años, en cuyo

${ }^{61}$ G. A. y otras vs. Ecuador (2020), considerando 139.

${ }^{62}$ Comité de los Derechos del Niño (2006), p. 7. 
caso se deberá probar la negligencia del agente directo para que el tercero civilmente responsable responda. Y, en tercer lugar, la hipótesis de niños cuya edad vaya desde los siete a dieciséis años en que responderán de la primera forma si se declara que actuaron sin discernimiento o, bien, como la segunda forma si se declarara que actuaron con discernimiento ${ }^{63}$.

En esta segunda modalidad, se incluye una alternativa al tercero civilmente responsable, para que acredite si con la autoridad y el cuidado que su respectiva calidad le confiere, no hubiere podido impedir el hecho. Esta exoneración para el caso de los padres ha derivado en el análisis de su deber de educación y vigilancia ${ }^{64}$. Al respecto, cabe destacar lo que ha entendido la doctrina argentina:

“[...] No significa estar siempre como un centinela sino que es educar con la palabra y con el ejemplo, es inculcar al menor el respeto al derecho ajeno, la mesura, la prudencia en el obrar, dando así la importancia que debe dársele al factor educativo en la formación y los hábitos de los menores, ello constituye la mejor vigilancia sobre su conducta futura" ${ }^{5}$.

Ahora bien, consideramos que el principio de autonomía y desarrollo progresivo de los NNA puede resultar esencial en una nueva elaboración del diagrama de responsabilidad. En un primer orden de ideas, es más consecuente con el principio de desarrollo progresivo el que la norma de responsabilidad no distinga por tramos de edades. Dado que esta situación encasilla al NNA en etapas de desarrollo típicas, pero que no toman en consideración su real desarrollo o la autonomía lograda en el caso en concreto $^{66}$. En un segundo orden de ideas, estimamos que el grado de desarrollo

${ }^{63}$ Pizarro (2017).

64 "No se trata que en ese suceso in concreto los padres hubieren podido evitarlo concurriendo a horas de la madrugada o impidiendo la salida de su hijo a esparcirse. De lo que se trata es si con el cuidado que les compete, en conjunto con los deberes de educación propios a la autoridad de los padres, dichas conductas no se condicen con lo que uno espera de los hijos bajo el amparo de la guarda de los padres". Indica Pizarro (2017) al analizar el fallo de Corte de Apelaciones Antofagasta, 27 de septiembre 2010, rol n. ${ }^{\circ} 466$ 2010, Westlaw CL/JUR/7782/2010.

${ }^{65}$ Boroffio y García (2002), p. 227.

${ }^{66}$ Un abordaje más completo implicará no solo tomar en cuenta la edad, sino que, también, la forma de tomar decisiones del niño "Mientras mayor el niño en cuestión, mayor el peso que el tribunal debe otorgar a sus deseos, ciertamente en el área del tratamiento médico. En un sentido, éste es solamente un aspecto de la aplicación del test de que la consideración primordial es el bienestar del niño. Generalmente será en el interés superior de un niño que tenga la suficiente edad y entendimiento para tomar una decisión informada, que el tribunal respete su integridad como ser humano y no invalide 
que alcanza el NNA debe ir en relación con la responsabilidad con la que deben responder sus padres. Así, por ejemplo, nada justifica la estrecha separación entre quien tiene quince años y once meses de quien tiene dieciséis años cumplidos, o aún la más radical diferencia en la atribución de responsabilidad entre quien tiene diecisiete años y once meses en relación con quien tiene dieciocho años cumplidos.

$\mathrm{Al}$ respecto, el Comité de los Derechos del Niño ha sido enfático en destacar que los Estados partes de la Convención no pueden partir de la premisa de que un niño sea incapaz de expresar sus propias opiniones, reconociendo de esa forma que la edad no es un buen criterio de distinción. Por eso, ha indicado que el art. 12 de la CDN no establece ningún límite de edad para que el niño pueda expresar su opinión, y, en consecuencia, que la edad en sí misma no puede determinar la trascendencia de las opiniones del niño o niña. Lo anterior, debido a que los niveles de comprensión de los niños no van ligados de manera uniforme con su edad biológica, sino que, dada las diferencias de experiencia, entorno y expectativas sociales y culturales, los análisis sobre la capacidad de comprender las consecuencias de un asunto determinado, debieran evaluarse en el niño o niña mediante un examen caso a caso ${ }^{67}$.

De acuerdo con lo expuesto, una norma de responsabilidad adecuada debe tomar en consideración la actuación de los padres, pues tampoco se justifica que respondan sin límite alguno por los hechos ilícitos de sus hijos menores de edad, como señalamos en el apartado anterior. Por ende, debe existir un límite que propenda al equilibrio entre el desarrollo alcanzado con la educación y crianza entregada y la autonomía del niño. Pero la norma de responsabilidad tampoco puede dejar de observar el fin de garantía que cumple la responsabilidad por el hecho ajeno. De tal manera, son tres los elementos que deben representar un papel preponderante en una política pública que determine la atribución de responsabilidad:

i) El desarrollo progresivo del NNA;

ii) La función de garantía para la víctima de la atribución de responsabilidad al tercero civilmente responsable y

iii) La participación o esfuerzos desplegados por los padres para lograr el desarrollo pleno del NNA.

Así, las reglas de responsabilidad que tomen en consideración el desarrollo progresivo del NNA deben solo dividirse en dos regímenes separados de responsabilidad.

a la ligera su decisión sobre un tema tan personal como el tratamiento médico, más aún si se está frente a un tratamiento invasivo". Court of Appeal W. WLR, 3, 1992, 758. En BRIDGEMAN (2017).

${ }^{67}$ Comité de los Derechos del Niño (2009), pp. 9-11. 
Un primer régimen debe implicar la responsabilidad directa de los padres del menor de edad y, para atribuir esta responsabilidad deberá tratarse de un NNA al que no es posible atribuir culpa, pues su nivel de desarrollo no le permite discriminar entre lo bueno o lo malo o, al menos, su actuación no puede ser calificada como culpable o negligente. Estos casos implicarán una responsabilidad directa de los padres, pero por un hecho ajeno, aunque respecto del agente directo del daño no pueda atribuirse responsabilidad.

El sistema actual de responsabilidad ha recibido ciertas críticas fundadas $^{68}$, debido a que el art. 2319 requiere probar la negligencia de los padres. Sin embargo, tratándose de hechos cometidos por NNA a los que no es posible atribuir negligencia, estimamos que no se debiera permitir a quien lo tiene a su cuidado la posibilidad de exonerarse en su diligencia, pues la diligencia no será suficiente para haber evitado el daño. En ese sentido, la comisión de un ilícito por una persona cuya conducta no es susceptible de ser calificada de negligente, nos parece suficiente para demostrar la negligencia del tercero. Por lo tanto, consideramos que debe aplicar un régimen de responsabilidad objetivo en estos casos. Siendo una excusa razonable sería de aquellas que rompen el vínculo causal, como la fuerza mayor, el hecho de un tercero o el hecho de la víctima.

El segundo régimen, estará determinado por el actuar negligente ${ }^{69} \mathrm{del}$ NNA y entonces deberán acreditarse todos los presupuestos de la responsabilidad respecto de él. En efecto, una norma que tome en consideración el desarrollo progresivo deberá implicar una responsabilidad más estricta de los padres en la medida que exista un grado menor de desarrollo del NNA y, en ese sentido, al alcanzar mayor autonomía, la responsabilidad de los padres debiera ser menos estricta.

Ahora bien, para no entrar en confusiones terminológicas, en los casos en que sea calificable el actuar del NNA como imprudente o negligente, la responsabilidad deberá ser por culpa. Asimismo, el régimen de responsabilidad deberá ser por culpa presunta respecto del tercero civilmente

${ }^{68}$ Corral (2017): "La mayoría de la doctrina piensa que la frase implica que se debe probar la culpa del guardián del incapaz, y ello revelaría que en tales casos no se aplica la presunción de responsabilidad por hecho ajeno del art. 2320. Pero esto genera el contrasentido de que mientras más chico sea el menor más difícil es imputar responsabilidad a los padres, lo que parece ir contra el sentido común"; PizArro (2017): "La necesidad de que la víctima acredite la culpa de quien tiene a cargo el incapaz ha permitido señalar que no estaríamos frente a una responsabilidad por el hecho de otro, sino más bien por el hecho propio, dada la circunstancia de que se exige probarle culpa al legitimado pasivo que tiene a su cargo al niño incapaz".

${ }^{69}$ Con ello referimos a un niño, niña o adolescente imputable civilmente en razón de su autonomía progresiva. 
responsable, de modo tal que sea este el que deba acreditar que desplegó todos los esfuerzos razonables para evitar que el NNA que tiene bajo su cuidado no causara daños.

Por último, el juez debiera tener en consideración, en cualquier caso, el grado de autonomía y desarrollo que ha logrado el NNA, así como el cuidado y educación entregada por los padres para la atribución de responsabilidad o como lo hemos señalado, el cumplimiento de sus deberes filiativos. Esto permite, por una parte, un equilibrio entre la responsabilidad de los padres con la responsabilidad de sus hijos menores de edad. Debido a que si los padres han realizado todo lo que está a su alcance y el actuar del NNA se desarrolla por un libre albedrío habiendo alcanzado un desarrollo que le permite actuar por sí mismo, no debieran ser sus padres responsables de los ilícitos civiles cometidos por sus hijos. Esto se liga, además, con que al conceder cierta autonomía y consciencia al niño o niña de que sus acciones van generando consecuencias (responsabilidad civil), se promueve que -atendido su nivel de desarrollo- avance hacia la independencia de sus padres y se responsabilice por susactos ${ }^{70}$.

\section{Conclusión}

El principal objetivo de este trabajo ha sido identificar tanto en el derecho constitucional comparado como en el derecho interno, la necesidad de consagrar en la nueva Constitución el reconocimiento expreso de los NNA y el principio de corresponsabilidad de sus padres. En ese sentido, observamos que una serie de países han incluido en su ley fundamental a los NNA como sujetos de derecho y algunas también abordan de forma directa la corresponsabilidad parental como, por ejemplo, la Constitución de Ecuador.

La forma de evidenciar la necesidad de esta regulación constitucional se ha desarrollado a partir del análisis de la responsabilidad civil de los padres por los hechos dañosos cometidos por sus hijos, mostrándose con dicho análisis que la regulación actual que entrega el Código Civil requiere una actualización que permita desprenderse de los criterios de subsidiariedad y habitabilidad en los términos que regula el art. 2320 del referido Código.

${ }^{70}$ Cabe precisar que esta es una decisión de política pública, pues debe afrontar la decisión de quién debe soportar el daño, ya sea el tercero civilmente responsable que lo tiene a su cuidado o la víctima del daño (por cierto, no es la idea que la víctima quede sin indemnización y, por lo mismo, debemos reconocer que en la mayoría de los casos el NNA carecerá de bienes suficientes para responder). 
En ese sentido, para reemplazar dichos criterios anacrónicos proponemos incluir el principio de corresponsabilidad parental y la autonomía progresiva del NNA. El primero, sirve para dotar de contenido al criterio de imputación subjetiva respecto del cual los padres habrán de responder en caso de que sus hijos cometan un ilícito civil. Así, cuando ambos padres acrediten que han dado cumplimiento a sus deberes paterno filiales, poniendo el interés superior del niño en el centro de su atención en pos de favorecer su desarrollo integral, podrán acceder a una exoneración de responsabilidad. De lo contrario, la corresponsabilidad importará que ambos padres soporten la indemnización.

Por lo demás, y por exceder el objetivo de este trabajo, hemos acotado que, en la fase de contribución a la deuda de cada padre, la nueva norma de responsabilidad civil de los padres podría incorporar criterios para que el adjudicador tome en consideración si ambos padres han colaborado de la misma forma en el desarrollo integral del niño o qué gastos ha realizado cada uno para efectos de una equitativa distribución de la responsabilidad. En definitiva, atribuir mayor responsabilidad de los daños al padre que estuvo ausente y no al que fue diligente y se preocupó del desarrollo integral de su hijo.

El segundo principio de autonomía progresiva del NNA implica que la nueva norma de responsabilidad civil que se ajuste a la nueva Constitución, deberá eliminar la referencia a edades de la niña o niño, y más bien incluir dos alternativas.

Primero, para el caso de que el niño tenga un desarrollo integral bajo, en el cual no sea posible la atribución de responsabilidad a su respecto, los padres deberán responder directamente, pues la sola comisión del daño para un niño con menor desarrollo integral implicará que los padres no han obrado con el cuidado y diligencia debida. Alterándose, entonces, el supuesto del actual art. 2319 en que la víctima debe acreditar la negligencia de los padres.

Segundo, que en aquellos casos en que el NNA sea susceptible de ser responsable civilmente, se mantenga una regla de presunción de culpa de los padres, para que en el caso de que estos puedan acreditar que han cumplido con sus deberes paterno filiales -le han entregado las herramientas, valores y principios para obrar de forma debida-, pero que atendida la autonomía que ha alcanzado el niño, aquel daño estaba fuera de su control. Dicho de otro modo, mientras menor sea el desarrollo y autonomía del niño, más estricta será la responsabilidad de los padres, pero mientras el NNA alcance un grado mayor de desarrollo, deberá flexibilizarse la responsabilidad de sus padres en la medida que ellos acrediten que han dado cumplimiento a sus deberes parentales. 
Para concluir, destacamos que el eventual reconocimiento constitucional de los NNA y la corresponsabilidad de los padres no solo impactará en el aspecto de responsabilidad civil que hemos abordado, sino que importará un claro avance hacia el cumplimiento de la normativa internacional de derechos humanos que consagra los derechos de los niños.

\section{BibLIOGRAFÍA CITADA}

AcuÑA, Marcela (2013). "El principio de corresponsabilidad parental". Revista de Derecho Universidad Católica del Norte, año 2, n. ${ }^{\circ} 20$. Coquimbo.

Acuña, Marcela (2020). "Los deberes de los padres respecto de sus hijos: Asegurando su protección y bienestar”, en Carmen Domínguez (ed.). Convención Internacional de los Derechos del Niño. Estudios y experiencias en Chile y Latinoamérica a 30 años de su vigencia. Santiago: Thomson Reuters.

Alessandri Rodríguez, Arturo (2005). De la responsabilidad extracontractual en el derecho civil chileno. Santiago: Editorial Jurídica de Chile.

Alferillo, Pascual (2013). "El proceso de Constitucionalización del Derecho Civil". Ratio Iuris, Revista de Derecho Privado, vol. 1, n. ${ }^{\circ} 1$. Buenos Aires.

Albornoz, Laura (2021). "La mujer como persona en el derecho civil chileno", en Natalia Morales y Hugo CÁrdenas (coords.). Feminismo, género y derecho privado. Valencia: Tirant lo Blanch.

BARros, Enrique (2020). Tratado de responsabilidad extracontractual. Santiago: Editorial Jurídica de Chile.

BASSA, Jaime (2018). "Reconocimiento constitucional de los derechos de niños, niñas y adolescentes". Presentación ante la Comisión de Constitución, Legislación, Justicia y Reglamento de la Cámara de Diputados. Martes 15 de mayo 2018. Disponible en www.camara.cl/verDoc.aspx?prmID=132225\&p rmTIPO=DOCUMENTOCOMISION [fecha de consulta: 10 de mayo de 2021].

BRidgeman, Jo (2017). "Responsabilidad: Protegiendo el bienestar y promoviendo la autonomía”, en Fabiola LaTHrop y Nicolás Espejo (coords.). Responsabilidad parental. Santiago: Thomson Reuters.

Bonilla Correa, Jesús (2009). La responsabilidad civil ante un ilícito penal cometido por un menor, aspectos sustantivos. Valencia: Tirant lo Blanch.

Boroffio, Natalia y Carlos García Santas (2002). "Responsabilidad de los padres por los daños producidos por sus hijos", en Graciela Medina, Daños en el derecho de familia. Buenos Aires: Rubinzal/Culzoni Editores.

Comité de los Derechos del Niño (2006). Observación general n. ${ }^{\circ}$ 7, Realización de los derechos del niño en la primera infancia. Disponible en ww2.oj.gob. gt/cursos/COMPILACION3/docs/Organos/Nino/Generales/OGnino7.pdf [fecha de consulta: 3 de julio de 2021]. 
Comité de los Derechos del NiÑo (2009). Observación general n. ${ }^{\circ}$ 12, El derecho del niño a ser escuchado. Disponible en www.acnur.org/fileadmin/Documentos/BDL/2011/7532.pdf [fecha de consulta: 3 de julio de 2021].

Comité de los Derechos del NiÑo (2013). Observación general n. ${ }^{0}$ 14, Sobre el derecho del niño a que su interés superior sea una consideración primordial. Disponible en www.defensorianinez.cl/wp-content/uploads/2019/03/OG14. pdf [fecha de consulta: 3 de julio de 2021].

Comité de los Derechos del NiÑo (2016). Observación general n. ${ }^{\circ}$ 19, Sobre elaboración de presupuestos públicos para hacer efectivos lo derechos del niño (art. 4). Disponible en www.redhnna.org/monitor/observacion-generalnum-19-2016-sobre-la-elaboracion-de-presupuestos-publicos-para-hacerefectivos-los-derechos-del-nino-art-4 [fecha de consulta: 3 de julio de 2021].

Comité para la Eliminación de la Discriminación contra la Mujer (2018). Observaciones sobre el séptimo informe periódico de Chile (CEDAW/C/ CHL/7) 14 de marzo de 2018. Disponible en https://acnudh.org/load/2018/ 07/N1807016.pdf [fecha de consulta: 1 de julio de 2021].

Contardo, Juan Ignacio (2020). "Responsabilidad de los padres por el hecho de los hijos”. Episodio 08: Fueyo Podcast. Disponible en https://anchor.fm/fueyo-podcast/episodes/Episodio-08-Responsabilidad-de-los-padres-por-elhecho-de-los-hijos-eatp6j/a-a1mb8do [fecha de consulta: 5 de abril de 2021].

Corral, Hernán (2013). Lecciones de responsabilidad civil extracontractual. Santiago: Thomson Reuters.

Corral, Hernán (2014). "Constitucionalización del derecho civil. Reflexiones desde el sistema jurídico chileno”, en Carlos Villabella, Leonardo Pérez y German Molina (eds.). Derecho civil constitucional. México: Grupo Editorial Mariel.

Corral, Hernán (2017). "Rompe, paga... papá”. Disponible en https://corraltalciani.wordpress.com/2017/06/18/rompe-paga-papa/ [fecha de consulta: 1 de abril de 2021].

Corral, Hernán (2018a). "Responsabilidad civil de ċlos padres?”, en El Mercurio Legal, Santiago, 15 de julio de 2018.

CORRAL, Hernán (2018b). "Constitucionalización del derecho civil, neoconstitucionalismo y activismo judicial”. Revista de Derecho Aplicado. LLMUC, n. ${ }^{\circ}$ 2. Santiago.

ETCHEBERRY, Leonor (2020). "Los niños, niñas y adolescentes merecen formar parte de la Constitución”. Disponible en www.latercera.com/opinion/noticia/ los-ninos-ninas-y-adolescentes-merecen-formar-parte-de-la-constitucion/MRRAEKL7HFHEVMNMF3BGQZ2SKQ/ [fecha de consulta: 4 de abril de 2021].

FERnÁndez, Miguel (2004). “Constitucionalización del derecho civil. Eficacia horizontal y renunciabilidad de los Derechos fundamentales". Temas de Derecho, n. ${ }^{\circ}$ 19. Santiago.

Gutiérrez Santiago, Pilar (2011). "La constitucionalización del derecho civil”. Estudios de Derecho, vol. LXVIII, n. ${ }^{\circ}$ 151. Medellín. 
LATHROP, Fabiola (2008). "Algunas consideraciones en torno a la custodia compartida de los hijos". Revista Chilena de Derecho Privado, n. ${ }^{\circ} 10$. Santiago.

LATHROP, Fabiola (2014). "La protección especial de derechos de niños, niñas y adolescentes en el derecho chileno”. Revista Chilena de Derecho Privado, n. ${ }^{\circ} 22$. Santiago.

LATHROP, Fabiola (2017). "Responsabilidad parental en casos de separación. Una mirada a las legislaciones latinoamericanas”, en Fabiola LATHROP y Nicolás EsPejo (coords.). Responsabilidad parental. Santiago: Thomson Reuters.

LÓPEZ DE LA CRUZ, Laura (2013). "Estructura general de la responsabilidad extracontractual”, en Ángel LóPEZ y LóPEZ y Rosario VALPUesta Fernández (eds.) y María Serrano Fernández (coord.). Tratado jurisprudencial de responsabilidad por daños. Valencia: Tirant lo Blanch.

Mendoza, Pamela (2019). "La responsabilidad de los padres por los daños cometidos por sus hijos menores como supuesto de pluralidad de responsables", en Alexis Mondaca y Cristián Aedo (eds.). Estudios de Derecho de Familia IV. Santiago: Thomson Reuters.

Meza Barros, Ramón (2009). Manual de las fuentes de las obligaciones. Santiago: Editorial Jurídica de Chile, tomo II.

Pegoraro, Lucio (2019). "Constitucionalización del derecho y cultura constitucional”. Revista de Derecho Político, n. ${ }^{\circ} 104$. Madrid.

Pizarro Wilson, Carlos (2017). "La responsabilidad civil de los padres por los daños ocasionados por sus hijos menores", en Fabiola LATHROP y Nicolás EsPejo (coords.). Responsabilidad parental. Santiago: Thomson Reuters.

RiziK Mulet, Lucía (2016). “¿ ¿Responden los padres por los daños ocasionados por sus hijos?”. Disponible en www.elmercurio.com/legal/noticias/opinion/2016/08/29/responden-los-padres-por-los-danos-ocasionados-porsus-hijos.aspx [fecha de consulta: 13 de abril de 2021].

Rizik Mulet, Lucía (2018). "Notas sobre la responsabilidad civil extracontractual de los niños", en Claudia Bahamondes, Leonor Etcheberry y Carlos Pizarro (eds.). Estudios de Derecho Civil XIII. Santiago: Thomson Reuters.

RızıK, Lucía (2021). "La responsabilidad civil de los padres". Boletín. Desde Bello hasta nuestros días, $\mathrm{n} .^{\circ} 165$. Valencia.

SAn MARTín, Lilian (2016a). "La responsabilidad civil de los padres por los daños causados por los hijos menores (parte I)". Disponible en www.elmercurio. com/legal/noticias/opinion/2016/06/20/la-responsabilidad-civil-de-los-padres-por-los-danos-causados-por-los-hijos-menores-parte-i.aspx [fecha de consulta: 3 de abril de 2021].

SAn Martín, Lilian (2016b). "La responsabilidad civil de los padres por los daños causados por los hijos menores (parte II)". Disponible en www.elmercurio. com/legal/noticias/opinion/2016/07/06/la-responsabilidad-civil-de-los-padres-por-los-danos-causados-por-los-hijos-menores-parte-ii.aspx [fecha de consulta: 3 de abril de 2021]. 
Tovani, Flavio (2012). "Familia y responsabilidad civil: reflexiones sobre la responsabilidad de los padres respecto de sus hijos y respecto de los terceros, en Italia”. Revista de Derecho de la Universidad Católica de Uruguay. Segunda época año 7, n. ${ }^{\circ}$ 7. Montevideo.

\section{Jurisprudencia citada}

D. C. J. A. y otro con P. U. C. A. y otra (2017): Corte Suprema, 5 de julio de 2018, rol n. ${ }^{\circ} 31974-2017$.

Reservado (2014): Corte Suprema, 23 de julio de 2014, rol n. ${ }^{\circ}$ 640-14.

R. E. y otros vs. Guatemala (2018): Sentencia Corte Interamericana de Derechos Humanos, 9 de marzo de 2018.

G. A. y otras vs. Ecuador (2020): Sentencia Corte Interamericana de Derechos Humanos, 24 de junio de 2020.

Siglas y ABREVIaturas

art. artículo

arts. artículos

214

$\mathrm{CADH}$ Convención Americana de Derechos Humanos

CDN Convención sobre los Derechos del Niño

CEDAW Convención sobre Eliminación de todas las formas de Discriminación contra la Mujer

CIDH Corte Interamericana de Derechos Humanos

coord. coordinadora

coords. coordinadores

DADH Declaración Americana de Derechos del Hombre

ed. editora

eds. editores

https Hypertext Transfer Protocol Secure

n. ${ }^{\circ}$ número

NNA Niños, Niñas y Adolescentes a veces Niño, Niña y Adolescente

OEA Organización de Estados Americanos

p. página 
pp. páginas

ss. siguientes

vol. volumen

vs. versus

www. World Wide Web 